\title{
Changing Technology, Emerging Development: Sustainable Development in Rural India through mobile telephony
}

\author{
Dr. Malik Zahra Khalid \\ Associate Professor, University of Kashmir, Jammu \& Kashmir \\ Dr. Aaliya Ahmed \\ Associate Professor, University of Kashmir, Jammu \& Kashmir \\ Abeen Bilal Shayiq \\ Students, Jamia Milia Islamia, New Delhi
}

\begin{abstract}
The correlation between technologies, sustainable development, socio-economic issues have assumed significance in the changing global world. In the new millennium, there is no denying the fact that information and communication technologies play a key role in the growth of a country. There is substantial evidence that technology has power to harbor progress as it affects many dimensions of societal and economic aspects like education, health, quality of life. It is pertinent to develop an understanding about the methods and techniques in which technology can be utilized to respond to the emerging paradigms of development in a responsible manner. Recent findings show that ICT plays a vital role in advancing economic growth and reducing poverty. ICT can be used to directly influence the productivity, cost effectiveness and competitiveness in industries. On the other hand, the results for not being able to recognize the benefits of ICT can also devastating. It can be inferred that without a strategic integrated approach it will be intricate to take advantage of the potential ICT driving the socioeconomic development. Originally built by Massachussetts Institute of Technology and funded by Gates Foundation, UN Democracy Fund and others, CGNet Swara as an online website was created with the goal of bringing development through mobile phones and interactive voice recording. CGNet Swara as a citizen journalism platform has huge implications for creating awareness, improving governance and spurring development not only in rural India but in other developing countries which are affected by poverty and poor social indicators. This paper focuses on the on the role and extent of information and communication technology (ICT) in socio economic development, highlighting the utilization of technology for sustained development, the reach of technology, the access to it in terms of use and consumption and the potential of technology as an enabler in the developing world.
\end{abstract}

Keywords: ICT4D, Socio-Economic Development, CGNet Swara

\section{Introduction}

Communication technology is a silver bullet for the development of the society especially the rural and marginalized sections of the society. Last few decades have seen a sea change in the socio-economic pattern of rural Indian societies. This phenomenal development in the rural pockets of population is largely because of the availability of the new tools of communication technology. Most of the government schemes could only uplift rural poor as they could use modern communication technology to bring change in their socio-economic status. Though traditional tools of communication technology like radio, television and print media have played their role but most of it has been cosmetic and insignificant and on the other hand new means of communication technology have played a far more influential role than the traditional ones. The growth rate has increased in such areas of population which were hitherto unconnected. We should be fair with the rural population that though traditional means of media helped them, but it was a very limited help. Mainstream media whether television channels or newspapers have not been able to provide the required space to the rural problems like the most recent agrarian distress witnessed suicides in hundreds by those farmers in rural India who could not pay back their debts to banks. Even their deaths in such large numbers could not move the mainstream media to provide them the space as the recent Balakote airstrikes are 
enough to prove what media is chasing in the current times. Even an event like Lakme Fashion Week is covered by 500 journalists. Most privileged members of the society get maximum coverage in newspapers, television and even in editorials. In order to provide an interactive platform to the rural population who are major stakeholders, where they can have their say and discussion on their problems and also provide solutions ICT can play a significant role. With the help of mobiles and internet they have got their answer to their problems. Mobile telephones can safely be described the real game changers of the present times. Internet has broken all barriers between the development and the rural poor. Coupled with thrust on the rural schemes by the central government, the internet has proved to be the real carrier of these schemes to the doorstep of every rural poor. Internet and mobile has already shown phenomenal success in the rural upliftment in the neighboring Bangladesh. After the micro financing system, mobile phones and internet were significant tools of modern communication to the rural poor of Bangladesh and it has played a key role to pull out a huge chunk of population out of clutches of abject poverty. The present paper attempts to reflect on the latitude of information and communication technology (ICT) in socio- economic development and therefore the focus is to review primarily a very modest technology using an interactive voice forum, CGNet Swara playing the role of subaltern media.

The entire narrative on CGNet Swara is built around the Positive Deviance Approach and Liberating Structures approach which is quite a departure from expert-driven models of Development Communication practice. The research design used was 'meta-analysis which is an analysis of data that has been previously collected, tabulated and analyzed by other researchers as how citizen journalism projects use ICT for news and information produced by communities in the far-flung and poorly resourced areas to bring about qualitative and measurable change. Our analysis is also drawn on the published posts under the impact section of the CGNet Swara website.

\section{ICT4D}

"The term ICT4D includes traditional or 'legacy' media as well as new digital technologies. Information and communication technologies (ICT's) comprise a complex and heterogeneous set of goods, applications and services used to produce, distribute process and transform information. ICT under its umbrella includes the outputs of industries as diverse as telecommunications, television and radio broadcasting, computer hardware and software, computer services and electronic media (e.g. the internet, electronic mail, electronic commerce and computer games" (Marcelle, 2000, p.5). This description admits that ICT's have evolved over a period of time and did not appear speedily either in the second half of the $20^{\text {th }}$ century or in the new millennium. In addition, ICT's include applications and not just hardware and gadgets. Castells (1999) in his discussion paper expresses that accessibility and practice of new communication and information technologies are essential forthe development of the entire globe adding they are as important as electricity was during the industrial revolution. ICT4D therefore generally refers to the possibilities created through the access to and use of ICT's for development as modernization. The United Nations through its various members of its family actively promotes ICT4D for socioeconomic development with a particular emphasis on helping poor and marginalized communities of the world. Critical perspectives on ICT4D emphasizes the use of new communication and information technologies for social change by involving citizen's participation and empowerment (Unwin, 2009, Melkote \& Krishnatray, 2010).

\section{Literature Review and Theoretical Background}

In the past several decades, especially since the 1970s, development communication practitioners and theorists of development communication have always focused on for the development of marginalized communities by developing better communication driven approaches for bringing about a social change (Dutta, 2008; Melkote \& Steeves, 2001; Servaes,2007). However, despite assertions by such experts, the realities on the ground border on all those concepts which exclude the basic stake holders that is the locals living in these areas. They are still rooted in the tenets of dominant paradigm following an expert- driven centralized approach (Zoller \& Dutta, 2008). 
All the initiatives taken for the community development under this approach were not focused on community development and were having no connected with common people. Hardly there were any efforts to bring out among the down trodden people who were a treasure of intellect and had other shining capacities. They are not calculated as entities with whom there can be dialogue, discussion and they could express their feelings. The present paper on mobile telephony as a tool of development taking the case study of CGNet Swara uses an alternative conceptualization of development communication practice, which turns the classical expert driven approaches on their head where the wisdom that lies with the most marginalized sections is discovered. This alternative approach is Positive Deviance and its stock is rising in social change praxis. "The positive Deviance (PD) approach is based on this very premise that in every community there are certain individuals or groups whose uncommon behavior and strategies enable them to find better solutions to problems than their peers, while facing worse challenges and having access to the same resources" (Singhal\& Dura, 2009). However, these people are normally unseen to others in the community.

The PD approach to social change brings out more and more positive deviant behaviors in the communities and also help them to find ways and means to multiply them. (Pascale, Sternin, 2010: Shafique, Singhal, 2013 Singhal, Buscelland Lindgerg, 2010; Singhal and Dura, 2012; Singhal, Sternin, \& Dura, 2009). Over the past few decades, the PD approach which is a substitute to diffusion of innovations approach has been effectively used to severe health and social issues like fighting malnutrition in Vietnam, minimizing the illegal trafficking of girls in Indonesia, minimizing the dropout rates in educational institutions of Argentina and US, lowering the rates of hospital assimilated infections in the US, Canada and Colombia (Pascale, Sternin, \&Sternin, 2010; Singhal\& Dura, 2009).. The PD approach postulates that there are always ideas within and role of change agents is to act as a catalyst to get them out. PD approach challenges the conventional theories and approaches which were on way and adopted atop down approach. PD is rooted in CGNet Swara whereby the tribals are made a part of the entire process of putting across their narratives on any of their issues. In the PD approach the community is not merely recipients of someone else's messages but is actively involved in the process of message formation, expansion and distribution. It makes people more a 'part of the processes' and they actually are. It doesn't tend to reverse the top-down process to bottom-up but rather integrate these two polar approaches.

Another approach the paper has used for the theoretical background of the present paper is the Liberating Structures Approach which again questions the modernization paradigm. "Liberating structures are simply simple procedures that groups can use to organize how they work or learn together" ( Singhal, Lipmanowicz, Wang,2015). Participation distribution to ensure everyone has an equal chance to contribute is the most important way to accomplish a goal (Lipmanowicz, Singhal, Wang, 2015). Include and set free everyone is the basic philosophy of liberating structures. Practice deep respect for people and local solutions. Engage the people doing the work and familiar with the local context. Liberating structures make it possible to stop all those practices that are encouraged in conventional microstructures. In simple terms, liberating structures doesn't require new and complex methodologies but simply make grassroots a part of the entire process. It engages everyone to build a good and sustained life. It encourages inclusion and engagement.

Many studies have been conducted by academicians, researchers and development communication planners to study the impact of telephones on rural and tribal development. Paul Mansingh's and Fikadu Abdese (2016) in their study revealed that mobile telephony has huge benefits for the agricultural and rural development in the developing world. Their study showed that mobile telephony has helped to address the problems of education, disaster risk management and rural finance in all those areas which are under developed. Mehta (2013) in his study has shown that mobile telephony has made lives of rural people better by keeping them informed about farming practices, bringing them closer to their relatives, friends and above all to their family members living out of their villages. 


\section{Objectives}

The objectives of the present study are as follows:

1. To highlight scope of information and communication technology (ICT) in socioeconomic development using an interactive voice forum.

2. To analyse and discuss selected research studies on information and communication for development (ICT4D) in India especially related to citizen journalism.

3. To assess the significance and role of CGNet Swara an interactive voice forum for the upliftment of the marginalized sections in India.

\section{Research Questions}

The paper seeks to examine the following research questions:

RQ1: How does a citizen journalism forum like CGNet Swara help the poor and marginalized people to get their dues?

RQ2: How does the coverage of issues by CGNet Swara mobilize government and mainstream media for collective action?

RQ3: What has been the impact of the interventions on the lives of poor and administration?

\section{Methodology}

The present study is aimed to assess and understand the impact of CGNet Swara as a subaltern media for bringing about change among the marginalized sections. The paper identifies the content analysis and qualitative textual analysis technique for achieving the objectives set out for the research. Drawing from meta analysis, data that has been previously collected, tabulated and analyzed by other researchers as how citizen journalism projects use ICT for news and information produced by communities in the far-flung and poorly resourced areas to bring about qualitative and measurable change has been used. A content analysis of the various research papers that have studied CGNet Swara as a voice forum for rural development was carried out. A textual analysis of eight stories posted under the impact section of the CGNet Swara website (http://cgnetswara.org/impact) that have made impact and helped to bring about a positive change in the lives of the people were also analysed. Only stories that were recorded in Hindi were taken for analysis. The authors selected the most recent recorded impact posts as of April, 2019. Qualitative textual analysis of the select stories highlighted the personal narratives of transformative benefits that CGNet Swara has brought to rural and tribal communities. Content analysis of the posts revealed the huge impact created by CGNet Swara has touched the lives that sat the bottom of the society.

\section{ICT4D initiatives in India --A Review}

For this paper the authors have selected few educational and development projects from SITE to cyber media carried out in India where huge chunk of population is constantly trying to come out of poverty and trying to make their lives better and where ICT4D has been a support to accelerate the adoption process of innovation. But most of the projects in which ICT4D intervention has contributed are experimental rather than operational ones. India's romance with ICT4D started with Radio Adult Education, popularly known as 'Radio Rural Forums' started by All India Radio in five district of Maharashtra to connect with rural population and which aimed to throw light on the questions surrounding the usefulness of radio as a means of adult education in rural India (Prasad, 2009). The summative impact evaluation survey carried out among the target group by Tata Institute of Social Sciences, Mumbai by Paul Neurath indicated positive outcome in which significant gains as a result radio listening was reported among educated and uneducated (Neurath Paul, 1962). The Satellite Instructional Television Experiment (SITE) is described as the "most extensive and social research project" (Vilanilam, 1996). This one year experiment was launched by ISRO on August 1,1975 and aimed to provide direct broadcasting and made it possible to take TV programme to distant and remote 2400 villages in six states of India. The summative impact assessment showed very few gains in several areas, whereas no impact in other areas (Agrawal, 1981). But it cleared that communication technology could be used for development and that programmes relevant to the needs and aspirations of rural and marginalized 
people were needed. Similarly Kheda Communication project which followed SITE was a model of locale based narrow casting project having participatory approach (Aggarwal, 1981). It relied heavily on audience participation. The TV programmes were made in the local Charautari dialect spoken by those villagers so as to educate them about their rights especially about their right to earn, to save them from exploitation. Many programmes focused on society of the villages for their cluster development. This decentralized project encouraged, holistic development in Keda District (Mayo and Servaes, 1992). It received the esteemed IPDCC UNESCO prize in 1984 for effective rural communication (Modi, 1991). Similarly, the Department of Electronics, Government of India launched CLASS as a pilot project during July 1984 in 250 schools spread all over the country to familiarize them with a range of computers and to develop a degree of ease and familiarity (Agrawal, 2012). The conventional media has been evaluated as more commercial in its approach and not constructively serving the needs and interests of the local community. According to communication philosopher and theorist Habermas, the crucial feature associated with expanded public spheres of democratic communication is the principle of nonexcludability. Democratization of media has yet to reflect the inclusive potential of communication. This has led to a search for marginal communication media that would provide better reach and access to media resources and empower the sidelined communities to be heard on their own terms and experiences. It is within this theoretical grounding that the community media has emerged as a powerful mass medium to connect communities and promote intercultural dialogue, multi culturalism and community interests (Prasad, 2009).

Community media has tried to percolate down to the grass roots in rural belts so as to cut down the short comings of mainstream media in these rural areas. Basically community media evaporates the lines which are false and highlights the experiences of local community and their groups highlighting their achievements". Community media is built around the core idea that communication works when it is grounded in the meaningful experience of the local community" (Prasad, 2009). In India where literacy remains a substantial barrier to development community radio can reach a large number of people because it is affordable and uses little electricity. Local All India Radio is airing the programmes being made by VOICES a group along with an NGO in Chitrguda in Southern Karnataka. These programmes are encouraging the locals to record their own radio programmmes thus getting a space. Among the successful Community Radio programmes is a popular programme "Our Voice". In this half an hour programme, there is a mix of local issues regarding their health, schooling, about their agriculture, education and above all women empowerment. There are several other organizations like the Deccan Development Society at Pastapur, VOICES in partnership with MYRADA at Kolar in Karnataka which have demonstrable models in community broadcasting (Uniyaal, 1999).

The end of the $20^{\text {th }}$ century was full of excitement generated by technological innovations of revolutionary scope and scale leading to digital transformation of the communication landscape, technological convergence, worldwide media coverage and the globalization of media content. Convergence is shaping up as the new paradigm and central symbol for future communications. The Indian communication industry is in the process of convergence of information and communication technologies which is full of amazing opportunities efficiency and growth in all spheres of activity. Though India's economy is still having a thrust on agriculture with $70 \%$ of its work force in this sector, it has crossed the threshold on an information revolution in the 1980's (Singhal\& Rogers, 1989). The access to a wide variety of text and graphic information has become possibly by using a computer, telephone and modem for homes. The traditional print media have also joined the convergence bandwagon with the appearance of virtual newsrooms and release of online newspapers and magazines in English and regional languages. Telemedicine is emerging as a major facility in several big medical institutions and hospitals. The e-governance initiatives were adopted by several State institutions in India on the premises that it would lead to more transparent and efficient citizen service. 
Major milestones in ICT4D Discourse at Global and National Level from earlier to present times

The discourse around the use of ICT's for development started with Daniel Lerner's 'Modernization Approach' (1958) which talks about the trust and confidence in power of technologies which ultimately led to the transformation of Europe from feudal, traditional societies to modern industrial, technological and militarized societies (Melkote \& Steeves,2001). Evert Rogers 'Diffusion of Innovations' talks about the notion of communicating development content and Wilbur Schramm's 'Magic Multiplier Approach' are the major approaches of communication for development. But unfortunately most of these technology driven approaches encompasses centralized and top-down process of reporting and communicating development. But the emphasis on the use of ICT's for development was discussed and debated in the Millennium Summit held in 2000 in New York city. The 192 member states agreed to sustain and enable communities, organizations and individuals through the use of ICT's (Steeves\&Kwami, 2012). The need for technological support to achieve the MDG's helped catalyze subsequent events including the then United Nations Secretary General Kofi Annans creation of a multi stake holder United Nations Information Communication Technologies Task force to multiply ICT4D such as internet governance. Additionally in 2002 Kofi Annan asked Silicon Valley to invent technologies appropriate and affordable for rural and marginalized sections. Similarly, other summits like World Summit on the Information Society (WSIS) and The Association for Progressive Communications through the use of communication technologies gave voice to the oppressed groups and made significant contributions to equitable human development, social justice and participatory processes (Klein 2005).

\section{Citizen Journalism in India}

Rodriguez (2001，20) theorized citizen Journalism "as a philosophy that encompasses a type of journalism that are a part of citizens everyday lives and thus the media produced is driven by the motives of these people". In mainstream Indian media, citizen journalists have started participating in different forms to share their communication with them. Many TV channels even show the footages uploaded by citizen journalists, mainly highlighting their day to day problems in their respective areas. Opinion polls being done by the channels get SMS polls also. There are many programmes like phone -in and also common people come in studio discussions which show greater interventions by common people in media. But citizen journalism so far comes in to play on TV and radio programmes mainly in extreme crisis situations like floods, tsunami's, communal riots violence etc. "Participation of common people in the media came via many radio entertainment programs and on television as citizen journalists giving their opinion through SMS, video footage or sending complaints or letters" (Sonwalker,2009). Citizen journalism in India has made its impact on television by bringing focus on gender bias, sexual harassment, violence against women, fears and violence against minorities (Allan, Sonwalker,and Carter 2007). The main citizen journalists sites in India include Merinews, The Citizen News Service which is in both Hindi and English (Thomas, 2011).

\section{CGNet Swara}

India has a huge population living in tribal areas spanning across from Bengal to Andhra Pradesh to Central state of Chhattisgarh. There are over 80 million tribals living in India without having any access or reach to media with their voices. While mainstream media has presence in this belt but most of the times their needs remain unfocussed. Moreover, it is corporate controlled and commercialized. This huge chunk of tribal population has remained in news or covered by media for all the wrong reasons like Maoist violence, a violent left wing movement. Public voices for their works remain unattended and their exploitation at the hands of vested interests remains as a grouse. This population is craving to tell their stories and to be part of progress as they have been passive spectators for decades. In order to give them a voice and space where they will feel not only the partnership but also the ownership CG Net Swara was an opportunity for them to get that space and come out of the shadows of neglect. The focus of the present paper is CGNet Swara launched in 2010 in Chattisgarh, a 
newly created small state in Central India that came into existence in 2000 having a population of 25 million inhabitants. Out of this more than 80 percent live in rural areas and are illiterate. Most of these tribals speak Gondi and Bilaali. CGNet Swara (CGNet stands for Central Gondwana Net, and Swara means "voice" in Sanskrit) is a voice based platform for citizen journalists to discuss issues related to Central Gondwana in Chattisgarh state. Founded in early 2010, CGNet Swara was mooted by Shubhranshu Choudhary, a journalist formerly working with the British Broadcasting Corporation $(B B C)$ as part of the Knight International Journalism Fellowships. (Pain, 2017) The project at present is managed with the help of grants from United Nations Democracy Fund and receives funds from Bill and Melinda Gates Foundation. In the words of its founder, "CGNet Swara is the people's website of Chattisgarh, where everybody is a journalist. It is a citizens journalism forum where the mission is the democratization of journalism". (Choudhary, 2009). In fact it has shifted the power of journalism to the mobile phone for these voiceless sections of the society. Using low cost mobiles, the village inhabitants can approach CGNet Swara to tell them about their grievances. They can also listen to the stories that fellow inhabitants have recorded. CGNet Swara has for the ease of locals simplified the messaging system with only two options. Option 1 is to record their grouse or grievance and other one is to listen to their message. Professional moderators edit their messages before uploading them on the channel (Mudliar, Donner, and Thies 2012). Once the message gets recorded from the field, editors accessing the system use a Web based interface to verify the report. Reports cleared by editors are then made available for rerun over the phone. They can also be accessed on the CGNet Swara site (Pain and Chen, 2019). CGNet Swara currently logs more than 500 calls per day (Pain, 2017). Even illiterate women from the village can participate and record their grievances. (Choudary, 2016).The site has a separate section for its impact stories and has over 500 stories at the last count (April, 2019). Issues most featured range from education, lack of proper drinking water, health, education, low wages and similar other developmental narratives. The grievances of the villagers are not only reported but a follow-up team keeps in touch with officials to ensure the redressal of their grievances (Marathe, Neill, Pain andThies,2015).

\section{Mobile telephony as a tool of development}

"The quickest way to get out of poverty right now is to have one mobile phone". Mohammad Yunus of the Grameen Bank (2011). Of all the ICT tools discussed mobile services have great potential in reaching out to the masses living in the socially and geographically isolated areas across the globe. Mobile telephony as the name suggests "is simply providing the services of telephone facility to instruments which are not fixed in one location and hence are mobile" (FAO). Mobile phones are connected with main mobile stations on ground. This communication on ground in turn keeps them connected with rest of the world. Services include voice messages, data roaming, SMS, streaming and location based services. In developing world the use of mobile phones has brought about notable change at the ground level. Whether its farmers checking weather updates, health treatments, getting connected with the village kiosk, rural finance mobile technology has opened up for a great number of people. Currently 95 percent of people living in the world are under mobile network coverage. An expected 90 percent of the phone subscriptions will be in the developing world by 2020 ('e-agriculture FAO Mobile Telephony in Rural Areas' FAO, 2011). It is expected that by 2022 there will be an estimated 829 million smart phone users in India which accounts for 60 percent of the country's population. Bangladesh was the first country to have used this rather cheap technology in the subcontinent. In 1997, Professor Yunus established Grameen Telecommunications, which provided a nationwide cellular network throughout Bangladesh. Grameen Phone network in Bangladesh has 50.000 ladies network who have been able to buy these phones with the help of banking finance available at the grass root level. (Singhal\& Rogers, 1989) . These "Telephone-ladies" operate their mobile pay phone business with cheapest rates in the world (Younus, 1999, p.226). Here "mobile" presence makes it possible for all village inhabitants to make and receive calls, averting the need to install expensive and large telephone exchanges. This has not only ensured voice communication between 
villages and with cities but has also resulted in growth and empowerment. Telecommunications services can also aid business activity and enhance the quality of life in rural areas as exemplified by the "telephone ladies" in Bangladesh. The concept of Grameen bank finance approach became a success because they did not treat the have not's in the society as mere consumers of communication technology but gave them the sense of ownership. This philosophy also explains the tremendous success of India's mobile telephony operating at grassroots level to provide telecommunication access to the socioeconomically disadvantaged sections of society (Singhal Rogers, 1989).

The remaining part of the paper is based on some important researches carried out in India and abroad in the last one decade or so. The present study has used meta-analysis approach or secondary analysis for understanding the impact. The authors analysed various research studies and project reports. Analysis of posts on CGNet Swara website was also done by the authors. Even news reports in mainstream newspapers have been analysed. To see the impact and usage of CGNet Swara Mudliar, Donner and Thies (2012) examined the initial usage of CGNet Swara. They analysed posts from the first 20 months of the project and conducted interviews with listeners, contributors, mainstream journalist as to how they perceived and used the system. Mudliar et al. (2012) highlighted how grievance redressal was an emergent and unexpected activity which seemed, even at an early stage to be the most impactful category of use. Mudilaar, Donnner (2012) also in another study reflected on CGNet Swara as a participatory mode of communication. Chandha and Steiner (2015) "examined the impact of CGNet Swara as a citizen journalism site, by conducting 10 in depth interviews with regional and national journalists to uncover their opinion on CGNet Swara". Overall they established that CGNet Swara was not successful in its goal of giving a platform to the tribal communities as stories were seldom taken up by mainstream news agencies or newspapers. Marathe, Neill, Pain and Thies (2016) in their study on ICT related initiative in Central India showed that such initiatives helps to resolve grievances in Central India. The study recommended that "citizen led initiatives serves as watch dog and an avenue for longer term grievances affecting a large number of people". The same study also recommended that "Its biggest impact has been convincing people that it can help solve issues. CG Net Swara helps them find a voice and more importantly solve issues to improve their quality of life". (Paromita, 2017). Pain and Chen (2019) in their study have concluded that CGNet Swara is playing a very important role by highlighting the issues and problems of those living in far flung tribal and rural belts and engaging those voiceless sections of the society who were excluded in main stream media platforms. CGNet Swara has been successful in empowering a marginalized society who is encouraged to find solutions to their problems themselves. Resolution of their issues as the participants post on the CGNet Swara website is the real impact of the entire initiative. For CGNet Swara news is about making a meaningful and measurable impact in the society. Frontline magazine (July 30-Aug. 12, 2011) reports that how CGNet Swara forced even main stream media to pickup news. This is an interesting story of Mahadev Singh Baiga tribal community person who lives in the forest hills of Bilaspur Chattisgarh. This village was not getting the working days under MGNREGA (Mahatama Gandhi National Rural Employee Guarantee Act) scheme. The villagers used to track 15 kilometers and the circle officer would always rebuke them. CGNet Swara did a miracle when four persons from the village got access to this mobile telephony network. Mahadev Singh one day recorded the circle officers rebuke and CGNet Swara published it in their bulletin. It created ripples in media circles and many mainstream newspapers and channels reported the incident forcing the authorities to give them their due. To show a concrete example of CG Net Swara impact the authors did textual analysis of some recent grievances that were reported and resolved via the system which not only added to their confidence but also generated interest in them. Surinder Sai a resident of remote village of Chattisgarh in the impact post of CGNet Swara is thanking the district authorities and Swara for mitigating the problem which was chronic from the last two decades, forcing the villagers to drink contaminated water. By the reach of programme this remotest village has been able to get clean drinking water (April 
29, 2019 post).Another post by Lakhan Singh of the same state, thanks CGNet Swara and district authorities for clearing their compensation case of perished buffaloes. Lakhan Singh in the post talks about the years he has been following the cases in tehsils and panchayat offices without any success (April 30, 2019 post). The study also analysed the posts on CGNet Swara to try to understand the impact of it on the lives of rural people. One such post is the perfect example how the CGNet Swara has boosted the self-confidence of poor rural people as they could get rice for the Anganwadi center which was hitherto not dispatched to them for last five months (www.cgnetswara.com) This post shows how SavitaRath from Raigarh was able to get proper food from Ministry of child and women welfare ministry for per-school poor children who needed it most (April, 302019 post). There are many more such stories detailed on CGNet Swara related to health crisis, fair wages and its impossible and beyond the scope of this paper for a comprehensive impact assessment.

\section{Conclusion}

This analysis extends our understanding of how dedicated ICT4D projects, characterized by strong participatory and dialogical elements bring about appositive change in the society. Information and Communication technologies have been used as a component in variety of strategies for solving different development problems and helping the weaker and marginalized sections of the community. In fact it has changed the development landscape in multiple ways. From participatory point of view and from the production side CGNet Swara has engaged and empowered communities. CGNet Swara as a mobile radio platform is viewed primarily as a low-cost loudspeaker. In the evolving technological revolution, radio as a means of communication has resurged and reinvented itself. FM, community radio, podcasting have given a new shape to this resilient platform. Introduction of low cost communication technology based projects like CGNet Swara regardless of their effectiveness as compared to alternative strategies may mobilize outside forces for them to achieve a substantial reallocation in priorities and can attract support. Information and Communication Technology related initiatives if used properly may serve as the organizing structure for educational, information or grievance redressal purpose, maintaining an innovative process over a period of time and reinforcing changes over a period of time. The ICT4D promise an equalizing of access to opportunities. Approaches like Positive Deviance and Liberating Structures hold significant implications for development communication practioners and scholars who generate discourses and narratives about issues and challenges faced by the weaker and unheard sections of the society. Rural people depend on communication with more populated areas for many reasons and aspects of their lives. All these relations with distant centres require communication. Such interaction can be accelerated substantially by communication technology and can make a qualitative difference in the lives of these marginalized sections.

\section{References:}

- Agrawal, B., C. (1981). SITE Social Evaluation: Results, Experiences and Implications Ahmedabad: Space Application Centre.

- Allan, S., Sonwalker, P., \& Carter, C.(2007). "Bearing Witness: Citizen Journalism and Human Rights Issues". Globalization, Societies and Education 5 (3): 373-389, doi: 10,1080/14767720701662139.

- Castelles. M. (1999). Information, technology, globalization and social development. Discussion Paper No.114.Geneva: United Nations Research Institute for Social Development. (UNRISD).

- Chadha, K., and L. Steiner (2015). "The Potential and Limitations of Citizen Journalism Initiatives: Chhattisgarh's CGNetSwara." Journalism Studies 16 (5): 706-718.

- Choudhary, S. (2009).CGNet and citizen journalism in India.E-Journal USA, 14(6), 42--43. Retrieved from http://www.america.gov/st/ people place-english/2009/June/ 20090616175845mlenuhret0.1840588.html on $20^{\text {th }}$ April 2019.

- Dutta, M. (2008). Communicating Health: A culture centred approach. London, UK: Polity Press'e-agriculture FAO Mobile 
Telephonyin Rural Areas': Food \& Agricultural Organization, 2011.

- Klein, H. (2005).Understanding WSIS: An institutional analysis of the U.N. World Summit on the Information Society. The Massachusetts Institute of Technology Information Technologies and International Development.1 (3-4),3-13.

- Lipmanowicz, H., Singhal, A., McCandless, K., \& Wang, H. (2015). Liberating Structures: Engaging everyone to build a good life together. In H. Wang (Ed.), Communication and "The good Life" (International Communication Association Theme) Book Series, Vol. 2, pp. 233-246). New York: Peter Lang.

- Mansingh, P,J., \&Erena, F, A. (2016). Impact of Mobile Phone Technology on Agriculture: An Analysis. In International Journal of Current Research, Vol. 8, 05,pp.31311- 31317, May, 2016.

- Marathe, M., O'Neill, J., Pain, P., \&Thies, W. (2012).Revisiting CGNetSwara and its impact in rural India.In Proceedings of the Seventh International Conference on Information and Communication Technologies and Development (p. 21). Singapore: ACM.

- Marathe, M., O'Neill, J., Pain, P., \&Thies, W. (2016). ICT-Enabled Grievance Redressal in Central India: A Comparative Analysis, ICTD, Ann Arbor, Michigan: USA.

- Marcelle, G.(2000). Transforming information and communication technologies for gender, Mehta equality. Gender and Development Series,\#NY:UNDP.

- Mayo, J.K \&Servaes, J. (1992). “Kheda Communication Project: An Indian Experiment in participatory broadcasting". UNESCO's orientation kit on Development Communication (Draft). Miami: Florida State University.

- Mehta,B.,S.(2016). Impact of Mobile Phone on Livelihood of People.Journal of Rural Development.Vol 35, Issue 3, JulySeptember, 2016.

- Melkote,S.,\&Krishnatray, P.(2010). Development Support communication in directed social change: a reappraisal of the theories and approaches. Paper presented to the $19^{\text {th }}$ annual conference of the Asian Media and Information Centre: Singapore, 20-23 June.

- Melkote, S \&Steeves, H.L. (2001). Communication for development in the third world: Theory and Practice for empowerment. Thousand Oaks, CA :Sage.

- Mudliar, P., J. Donner, and W. Thies. (2012). Emergent practices around CGNetSwara,

voiceforumforcitizenjournalisminruralIndi a.InProceedingsoftheFifthInternationalCo nference on Information and Communication Technologies and Development (pp. 159- 168).AMIC.

- Mudliar, P., \&Donner.J.(2015). Experiencing interactive voice response (IVR) as a participatory medium: The case of CGNetSwara in India.Mobile Media $\mathcal{E}$ Communication, in press.

- Neurath, P.M. (1962). Radio rural forum as a tool of change in Indian Villages.Economic Development and Cultural Change, 10: 275-83.

- Pain, P., Chen.M.C. (2019). 'A chance for me to do good, make a real difference': how citizen journalists in India view their role in social transformation, Media Practice and Education, DOI: 10.1080/25741136.2018.1556543.

- Pain, P. (2017).“Education. Empower. Revolt: Framing Citizen Journalism asa creator of Social Movements".Journalism Practice, 12 (7):799-816.

- Pscale, R.,T., Sternin,J. \&Sternin, M. (2010). The power of positive deviance: Hoe unlikely innovators solve the world's toughest problems: Boston, MA: Harvard University Press.

- Prasad, K. (2009). Communication for Development: Reinventing Theory and Action. B. R Publishing House: Delhi.

- Rodriguez, C. (2001). Fissures in the Mediascape: An International Study of Citizens' Media:

- Cresskill, NJ: Hampton Press. 
- Servaes, J. (Ed.) (2007). New approaches to communication for development and social change. New Delhi: Sage.

- Shafique, M., Sternin, M., \&Singhal, A. (2010). Will Rahima's firstborn survive overwhelming odds? Positive deviance for maternal and newborn care in Pakistan.

- Singhal, A., Buscell, P.,\&Lindberg, C. (2010). Inviting everyone: Healing healthcare through positive deviance. Bordentown, NJ: PlexusPress.

- Singhal, A., \& Dura, L. (2009). Protecting children from exploitation and trafficking: Using the Positive Deviance approach in Uganda and Indonesia. Washington D.C: Save the Children.

- Singhal, A.,\& Rogers, E.M. (1989). India's Information Revolution. New Delhi.Sage.

- Sonwalker, P. (2009). “Citizen Journalism in India: The Politics of Recoginition". In Citizen Journalism Global Perspectives, edited by S. Allan and E. Thorsen, 75-84, New York, NY:Peter Lang.

- Steeves.H.L. \&Kawami.D.J. (2012). ICT4D, Gender Divides and Development: The case of Ghana. Development Communication in Directed Social Change: A Reappraisal of Theory and Practice, 2012, Asian Media and Information Centre.

- Sternin, J. (2003). Positive Deviance (PD) student retention of educational enhancement program, Tufts University: Boston.
- Thomas, P.N. (2011). Negotiating Communication Rights: Case Study from India. New Delhi: Sage.

- Uniyal, M. (1999).“Radio for the marginalized" Humanscape, June p.28.

- Unwin, T. (2009). ICT4D: Information and communication technology for development. London: Cambridge University Press.

- Vilanilam, J.V. (1996). “The socio-cultural Dynamics of Indian Television: From SITE to Insight to Privatisation". In David French and Michael (Eds).Contemporary Indian Television: Eastern Perspectives. New Delhi: Sage.

- Yunus, M.(1999). Banker to the poor: Microlending and the Battle against Poverty. New York: Public Affairs.

- Zoller, H., \&Dutta, M. (Eds). (2008). Emerging perspectives in health communication: Meaning, culture, and power: New York: Routeledge

\section{Notes}

- (http://cgnetswara.org/about.html) retrieved on $12^{\text {th }}$ March, 2019. http:/ CGNetswara.org.html retrieved on $12^{\text {th }}$ March, 2019

- http://CGNetswara.org/index.php?id=5 25972 retrieved on $20^{\text {th }}$ April, 2019 http://CGNetswara.org/impact2.php retrieved on 30th April, 2019

- Govt of India Statistics (NHDR Survey 2018). Frontline agazine (July 30-Aug. 12,2011) 